\title{
PENINGKATAN DERAJAT KESEHATAN LANSIA PENDERITA HIPERTENSI MELALUI TERAPI TERTAWA
}

\author{
Dene Fries Sumah $^{1 *}$, Lydia Maria Ivakdalam¹, Donny Japly Pugesehan ${ }^{1}$ \\ Program Studi Keperawatan, Fakultas Kesehatan, Universitas Kristen Indonesia Maluku, Ambon, Indonesia \\ *Penulis Korespodensi : ristoisfrisco_peea@yahoo.com
}

\begin{abstract}
Abstrak
Periode lansia merupakan periode kehidupan yang rentan terhadap penyakit akibat mengalami perubahan fungsi tubuh dan berdampak pada terjadinya penyakitdegeneratif seperti Hipertensi. Hipertensi merupakan penyakit kronis yang jika tidak dikelola dengan tepat dapat menyebabkan komplikasi penyakit lainnya. Hipertensi membutuhkan penanganan yang komprehensif dalam mengontrol tekanan darah baik secara farmakologis dan nonfarmakologis, salah satunya adalah pendidikan kesehatan dan terapi tertawa.Kegiatan pengabdian masyarakat ini bertujuan untuk memperluas wawasan tentang pentingnya kesehatan bagi lansia melalui modifikasi faktor risiko atau pengelolaan gaya hidup serta pencegahan melalui terapi tertawa. Kegiatan ini dilaksanakan di Negeri Waai Kecamatan Salahutu Kabupaten Maluku Tengah. Metode yang digunakan yaitu mulai dari pengukuran tekanan darah, penyuluhan, training of trainer terapi tertawa bagi kader posyandudan lansia serta praktek terapi tertawa. Hasil dari kegiatan ini adalah lansia mengalami penurunan tekanan darah setelah diberikan terapi tertawa serta mampu melakukan terapi tertawa secara mandiri. Selain itu lansia semakin antusias untuk datang ke lokasi kegiatan, hal ini terbukti dari daftar kunjungan dan keaktifan lansia dalam mengikuti seluruh rangkaian kegiatan mulai dari registrasi, pengukuran tekanan darah, praktek terapi tertawa dan dilanjutkan dengan pemeriksaan kesehatan secara rutin.
\end{abstract}

Kata kunci: Lansia; Penyuluhan; Training of trainer; Pengukuran Tekanan Darah; Terapi Tertawa.

\begin{abstract}
The elderly period is a period of life that is susceptible to illness due to changes in bodily functions and has an impact on the occurrence of degenerative diseases such as hypertension. Hypertension is a chronic disease which, if not managed properly, can cause other complications. Hypertension requires comprehensive treatment in controlling blood pressure both pharmacologically and nonpharmacologically, one of which is health education and laughter therapy. This community service activity aims to broaden insights on the importance of health for the elderly through modification of risk factors or lifestyle management and prevention through laughter therapy. This activity was carried out in Waai Negeri Salahutu District, Central Maluku Regency. The method used is starting from measuring blood pressure, counseling, laughter therapy training for trainers for elderly cadres and practice of laughter therapy. The results of this activity are the elderly experiencing a decrease in blood pressure after being given a laugh therapy and being able to do laugh therapy independently. In addition, the elderly are more enthusiastic to come to the location of the activity, this is evident from the list of visits and activeness of the elderly in participating in a whole series of activities ranging from registration, blood pressure measurement, laughter therapy practice and continued with routine health checks.
\end{abstract}

Keywords: Elderly; Counseling; Training of trainers; Blood Pressure Measurement; Laughter Therapy.

\section{PENDAHULUAN}

Periode lansia merupakan periode kehidupan yang rentan terhadap penyakit akibat mengalami perubahan fungsi tubuh dan berdampak pada terjadinya penyakit degeneratif seperti Hipertensi, kelainan jantung, penyakit diabetes mellitus dan lain-lain. Pemerintah selalu berupaya untuk menjaga kesehatan bagi lansia dengan menjamin ketersediaan fasilitas pelayanan kesehatan dan memfasilitasi kelompok lansia seperti Puskesmas (Yogiantoro, 2016). Akan tetapi, lansia sendiri kurang dapat memanfaatkan pelayanan kesehatan yang ada karena jarak yang cukup jauh. Kelompok Lansia Puncak Damai Negeri Waai, merupakan mitra Program Kemitraan Masyarakat (PkM) yang dipilih oleh tim pelaksana berdasarkan hasil diskusi dan observasi langsung dengan mitra. Kelompok Lansia Puncak Damai Negeri Waai, berada di Kecamatan Salahutu Kabupaten Maluku Tengah, dengan jarak $\pm 32 \mathrm{~km}$ dari Universitas Kristen Indonesia Maluku. Kelompok Lansia Puncak Damai 
Negeri Waai merupakan wadah kesehatan yang dibentuk berdasarkan hasil Rancangan Program Kerja Negeri yang bertujuan untuk meningkatkan kesadaran para lansia untuk membina sendiri kesehatannya baik kesehatan fisik dan psikologis, meningkatkan kemampuan dan peran serta keluarga dan masyarakat dalam mengatasi kesehatan lansia, meningkatkan jenis dan jangkauan pelayanan kesehatan lansia serta meningkatkan mutu pelayanan kesehatan lansia. Hipertensi atau tekanan darah tinggi merupakan suatu penyakit kronis yang sering disebut silent killer karena pada umumnya pasien tidak mengetahui bahwa mereka menderita penyakit hipertensi sebelum memeriksakan tekanan darahnya (Jerome, 2017). Salah satu masalah serius yang terjadi dikalangan lansia saat ini adalah tingginya kejadian Penyakit Tidak Menular yaitu Hipertensi yang dapat mempengaruhi kesehatan fisik maupun psikologi lansia. Berdasarkan data (Riskesdas, 2018), Prevelensi penyakit Hipertensi di Indonesia berada pada urutan nomor satu dengan prevelensi Umur 55-64 Tahun 45,9\%, umur 65-74 Tahun 57,6\%, umur 75+ Tahun 63,8\%. Sedangkan berdasarkan data kunjungan lansia saat pemeriksaan kesehatan pada Puncak Damai Negeri Waai pada tahun 2019ditemukan bahwa rata-rata lansia berumur 45-75 tahun yang menderita hipertensi sebanyak 32 orang (Litbang, 2019).

American Heart Association menyatakan bahwa hipertensi hanya mampu dicegah perkembangannya melalui modifikasi faktor risiko atau pengelolaan gaya hidup, dan ini merupakan tindakan preventif utama dalam pencegahan terjadinya hipertensi. Upaya yang dilakukan dapat berupa terapi farmakologis ataupun non farmakologi. Terapi farmakologi melalui pemberian obat anti Hipertensi akan tetapi dapat menimbulkan beberapa kerugian antara lain efek samping, efek ketergantungan, tingginya biaya dan masalah lainnya yang semakin memperberat pasien lansia (Flynn, 2016). Sedangkan penatalaksanaan hipertensi yang dianjurkan bagi lansia adalah terapi nonfarmakologis, antara lain perubahan gaya hidup seperti diet rendah garam, olahraga yang disarankan untuk hipertensi seperti jalan pagi secara teratur, mengurasi konsumsi alkohol bagi pecandu minuman keras, berhenti merokok dan ada beberapa terapi yang sarankan guna menurunkantekanan darah seperti senam jantung sehat, terapi musik, terapi rendam air hangat, terapi pijat refleksi kaki dan terapi tertawa yang sudah banyak diketahui di masyarakat (Association, 2015).

Dari sejumlah terapi nonfarmakologi, terapi tertawa merupakan salah satu terapi yang mempunyai banyak manfaat dari berbagai segi. Dari segi ekonomis, tertawa tidak membutuhkan biaya. Sedangkan dari segi sosial, tertawa dapat membangun hubungan dengan baik dan mengatasi perselisihan (Sumah, 2019). Tertawa bukanlah suatu hal yang dilarang, selama masih dalam batas kewajaran dan normal tertawa tidak akan berdampak buruk karena yang berpengaruh negatif bagi tertawa yang melampaui batas (Tage, 2014). Tertawa 20 menit setara dengan berolaraga ringan selama 2 jam karena dengan tertawa peredaran darah dalam tubuh lancar, kadar oksigen dalam tubuh meningkat dan tekanan darah akan normal (Satish, 2012). Terapi tertawa dapat merelaksasikan tubuh yang bertujuan melepaskan endhorpin kedalam pembuluh darah sehingga apabila terjadi relaksasi maka pembuluh darah akan mengalami vasodilatasi sehingga tekanan darah dapat turun (Cheryl., 2014). Terapi tertawa adalah suatu terapi untuk mencapai kegembiraan di dalam hati yang dikeluarkan melalui mulut dalam bentuk suara tawa atau senyuman yang menghiasi wajah, perasaan hati yang lepas dan bergembira, dada yang lapang, peredaran darah yang lancar sehingga dapat mencegah penyakit dan memelihara kesehatan (Tage, 2014).

Mencermati realita yang ada maka tim Program Kemitraan Masyarakat (PkM) berinisiatif untuk mendekati Kelompok Lansia Puncak Damai Negeri Waai, Kecamatan Salahutu, Kabupaten Maluku Tengah untuk mendiskusikan masalah-masalah lansia. Dari hasil diskusi, terlihat bahwa banyak sekali permasalahan yang terjadi dari kelompok mitra yaitu: Tingginya angka kejadian hipertensi yang diderita lansia Puncak Damai Negeri Waai; Kurang adanya promosi kesehatan berupa sosialiasi/penyuluhan tentang penyakit tidak menular dalam hal ini adalah Hipertensi bagi lansia; Tidak adanya program pencegahan hipertensi secara non farmakologi atau komplementer dari petugas kesehatan yang diajarkan kepada kader/pengelola kelompok lansia; Rendahnya pengetahuan dan kesadaran lansia tentang peningkatan kualitas hidup lansia sehat yang masih rendah yang dibuktikan dengan jarang mengunjungi posyandu lansia tiap bulan berjalan.

Hal ini tentunya menjadi masalah serius karena pentingnya membudayakan gaya hidup sehat (life style) sejak dini kepada lansia, sehingga dapat mencegah berbagai gangguan kesehatan. Setelah berdiskusi dan mempelajari persoalan yang terjadi pada lansia di Kelompok Lansia Puncak Damai Negeri Waai maka disepakati bersama bahwa akan diadakan 1 kali seminar, 1 kali training of trainer terkait pencegahan Hipertensi secara non faramakologi melalui Terapi Tertawa, pengukuran tekanan darah bagi lansia dan praktek terapi tertawa bagi lansia. IPTEK yang akan diimplementasikan pada mitra PkM Kelompok Lansia Puncak Damai Negeri Waai adalah: Seminar terkait Penyakit Tidak Menular yaitu Hipertensi serta cara penatalaksanaannya bagi lansia; Mitra juga akan dilatih (Training of trainer) tentang pencegahan nonfarmakologi berupa Terapi Tertawa bagi lansia; Mitra juga akan dibantu untuk dilakukan pengukuran Tekanan Darah secara Cuma-Cuma; Setelah semua di atas, mitra akan diperkenalkan dan diajarkan cara melakukan terapi non farmakologi melalui praktek Massal Terapi Tertawa.

\section{BAHAN DAN METODE}

Dalam kegiatan Pengabdian Kemitraan Masyarakat (PkM) ini, tim memberikan edukasi berupa penyuluhan dan menyampaikan pesan-pesan menggunakan media 
poster kepada masyarakat khususnya usia lansia terkait Hipertensi dan Penatalaksaannya. Selain itu kami juga memberikan konseling terkait kesehatan fisik. Dengan adanya edukasi yang didapatkan oleh lansia, diharapkan lansia dapat menjaga kesehatan dan mengantisipasi risiko yang ditimbulkan akibat Hipertensi. Hipertensi dapat diketahui dengan adanya suatu pemeriksaan kesehatan, sehingga pada kegiatan yang kami lakukan tidak hanya memberikan edukasi tetapi juga memberikan pemeriksaan kesehatan secara gratis untuk dapat mengetahui kondisi lansia. Pemeriksaan kesehatan meliputi pemeriksaan tekanan darah dan pemeriksaan fisik. Bahan yang digunakan dalam pemeriksaan tekanan darah lansia berupa Tensi meter lapangan dan steteschope GEA disertai alat-alat kesehatan lainnya. Tim juga melakukan training of trainer (TOT) atau pelatihan bagi pengelola Kelompok Lansia untuk melakukan Terapi Tertawa dan dilanjutkan dengan melakukan Terapi Tertawa bagi Lansia penderita Hipertensi secara massal sehingga dapat diterapkan secara rutin dan berkelanjutan dengan inovasi-inovasi kegiatan yang tidak monoton.

\section{HASIL DAN PEMBAHASAN}

Kegiatan ini diselenggarakan pada bulan Oktober 2019. Pengabdian masyarakat dilakukan di Puncak Damai Negeri Waai, berada di Kecamatan Salahutu Kabupaten Maluku Tengah. Sebelum dilakukan penyuluhan bagi lansia diawali terlebih dahulu dengan Pre-test bagi lansia melalui pengisian kuisioner. Soal Pre-test dan Post-test merupakan soal yang sama dan bertujuan untuk mengetahui tingkat pengetahuan tentang hipertensi dan pencegahannya. Tingkat pengetahuan lansia mengenai hipertensi dan pencegahannya sebelum penyuluhan (Pre-test) yaitu kurang sebanyak 17 orang (53\%) dan sebagaian memiliki pengetahuan cukup sebanyak 15 orang $(47 \%)$. Kemudian tim melanjutkan dengan memberikan penyuluhan bagi lansia tentang pencegahan hipertensi melalui terapi nonfarmakologi melalui terapi tertawa sekaligus training of trainer bagi pengelola kelompok lansia tentang terapi tertawa pada tanggal 14 Oktober 2019.

Tabel 1. Distribusi Frekuensi Hasil Pre-Test Hipertensi dan Pencegahannya.

\begin{tabular}{|l|c|c|}
\hline Kategori & Jumlah (f) & Persentase (\%) \\
\hline Baik & 0 & 0 \\
\hline Cukup & 15 & 47 \\
\hline Kurang & 17 & 53 \\
\hline Total & 32 & 100 \\
\hline
\end{tabular}

Sumber : Data Primer, 2019.

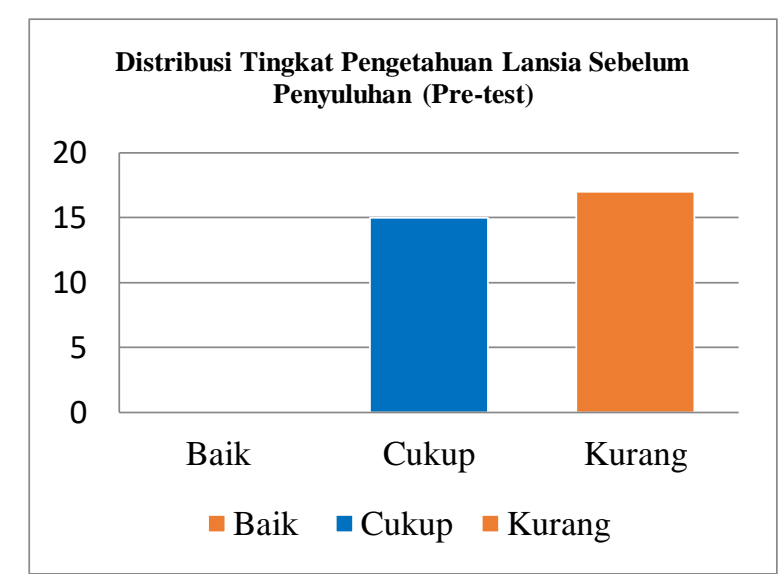

Diagram 1. Hasil Pre-test Hipertensi dan Pencegahannya.

Hasil pretest menunjukkan bahwa sebagian besar lansia memiliki tingkat pengetahuan kurang tentang Hipertensi dan pencegahannya. Hal ini disebabkan karena belum adanya program promosi kesehatan dari petugas kesehatan bagi kelompok lansia. Penyuluhan tentang hipertensi dan pencegahannya melalui terapi tertawa diharapkan dapat membantu meningkatkan pengetahuan para lansia.

Setelah dilakukan penyuluhan tentang hipertensi dan pencegahannya melalui terapi tertawa, lansia diberikan soal post-test. Hasil post-test menunjukkan bahwa lansia sebanyak 32 orang atau (100\%) memiliki pengetahuan yang baik tentang Hipertensi dan pencegahannya.

Tabel 2. Distribusi Frekuensi Hasil Post-Test Hipertensi dan Pencegahannya.

\begin{tabular}{|l|c|c|}
\hline Kategori & Jumlah (f) & Persentase (\%) \\
\hline Baik & 32 & 100 \\
\hline Cukup & 0 & 0 \\
\hline Kurang & 0 & 0 \\
\hline Total & 32 & 100 \\
\hline
\end{tabular}

Sumber : Data Primer, 2019.

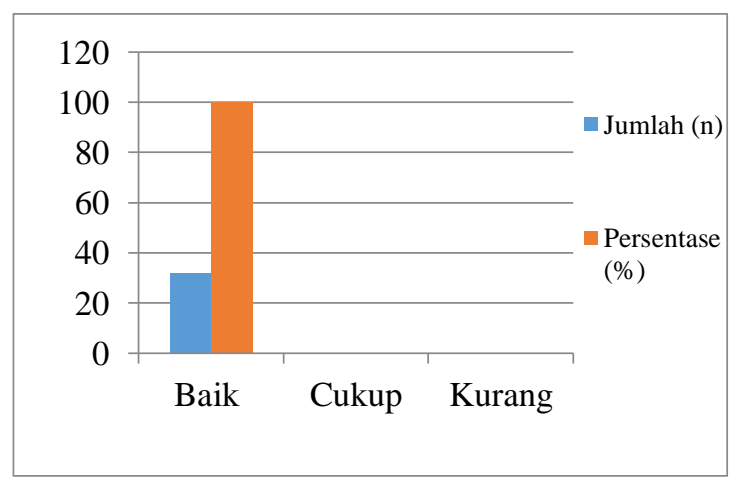

Diagram 2. Hasil Post-test Hipertensi dan Pencegahannya.

Hasil post-test menunjukkan bahwa lansia memiliki tingkat pengetahuan baik tentang Hipertensi dan pencegahannya. Tim juga melakukan uji T-test pada tabel dibawah ini: 
Tabel 3. Hasil Uji T-Test.

\begin{tabular}{|c|c|c|c|c|c|c|c|}
\hline & & Mean & N & $\begin{array}{c}\text { Std. } \\
\text { Deviation }\end{array}$ & $\mathbf{t}$ & df & $\begin{array}{c}\text { Sig. (2- } \\
\text { tailed) }\end{array}$ \\
\hline \multirow{2}{*}{$\begin{array}{c}\text { Pair } \\
1\end{array}$} & Pre-Test & 78,278 & 32 & 10,567 & & & \\
\cline { 2 - 7 } & Post-Test & 96,326 & 32 & 7,326 & $-19,152$ & 32 & 0,000 \\
\hline
\end{tabular}

\section{Sumber : Data Primer, 2019}

Hasil analisis pada tabel 3 menunjukkan bahwa ratarata nilai pengetahuan lansia sebelum mendapat penyuluhan (pre-test) adalah 78,278 dengan standari deciasi 10,567 dan sesudah mendapat penyuluhan (post-test) adalah 94,048 dengan standar deviasi 7,326. Hasil uji $\mathrm{T}$ berpasangan yang terlihat pada tabel 3.5 juga menunjukkan bahwa nilai $p$ valueyang dapat dilihat pada sig ( 2 tailed) adalah 0,000 yang berarti bahwa ada perbedaan yang signifikan antara pengetahuan pre-test dan pengetahuan post-test.

Kemudian tim melanjutkan dengan kegiatan pemeriksaan tekanan darah dan pemeriksaan kesehatan lainnya bagi tiap lansia pada tanggal 17 Oktober 2019. Adapun hasil pengukuran tekanan darah sebelum dan sesudah terapi tertawa dapat dilihat pada tabel 4 dibawah ini:

Tabel 4. Hasil Pengukuran Tekanan Darah sebelum dan Setelah dilakukan Terapi Tertawa.

\begin{tabular}{|c|c|c|c|c|c|}
\hline \multirow[t]{2}{*}{ No } & \multirow[t]{2}{*}{$\begin{array}{c}\text { Kode } \\
\text { Peserta }\end{array}$} & \multicolumn{2}{|c|}{$\begin{array}{c}\text { Tekanan Darah } \\
\text { Sebelum Terapi } \\
\text { Tertawa } \\
\end{array}$} & \multicolumn{2}{|c|}{$\begin{array}{c}\text { Tekanan Darah } \\
\text { Setelah Terapi } \\
\text { Tertawa } \\
\end{array}$} \\
\hline & & Sistolik & Diastolik & Sistolik & Diastolik \\
\hline 1 & P001 & $140 * * *$ & $110 * * * *$ & $120 * *$ & $80 * *$ \\
\hline 2 & P002 & $140 * * *$ & $110 * * * *$ & $120 * *$ & $80 * *$ \\
\hline 3 & P003 & $130 * *$ & $110 * * * *$ & $110^{*}$ & $70 *$ \\
\hline 4 & P004 & $140 * * *$ & $100 * * * *$ & $120 * *$ & $80 * *$ \\
\hline 5 & P005 & $159 * * *$ & $130 * * * *$ & $120 * *$ & $80 * *$ \\
\hline 6 & P006 & $140 * * *$ & $110 * * * *$ & $110^{*}$ & $75^{*}$ \\
\hline 7 & P007 & $150 * * *$ & $120 * * * *$ & $120 * *$ & $70 *$ \\
\hline 8 & P008 & $150 * * *$ & $110 * * * *$ & $110^{*}$ & $80 * *$ \\
\hline 9 & P009 & $130 * *$ & $100 * * * *$ & $120 * *$ & $80 * *$ \\
\hline 10 & P010 & $140 * * *$ & $120 * * * *$ & $120 * *$ & $70^{*}$ \\
\hline 11 & P011 & $160 * * * *$ & $130 * * * *$ & $120 * *$ & $80 * *$ \\
\hline 12 & P012 & $150 * * *$ & $110^{* * * *}$ & $110^{*}$ & $80 * *$ \\
\hline 13 & P013 & $150 * * *$ & 120 **** & $120 * *$ & $75^{*}$ \\
\hline 14 & P014 & $160 * * * *$ & $130 * * * *$ & $120 * *$ & $70 *$ \\
\hline 15 & P015 & $145 * * *$ & $100 * * * *$ & $110 *$ & $80 * *$ \\
\hline 16 & P016 & $145 * * *$ & $115 * * * *$ & $120 * *$ & $80 * *$ \\
\hline 17 & P017 & $150 * * *$ & $100 * * * *$ & $120 * *$ & $70 *$ \\
\hline 18 & P018 & $160 * * * *$ & $130 * * * *$ & $120 * *$ & $80 * *$ \\
\hline 19 & P019 & $170 * * * *$ & 120 **** & $110^{*}$ & $80 * *$ \\
\hline 20 & P020 & $160 * * * *$ & $110 * * * *$ & $120 * *$ & $75^{*}$ \\
\hline 21 & P021 & $140 * * *$ & $120 * * * *$ & $120 * *$ & $70 *$ \\
\hline 22 & P022 & $160 * * * *$ & $120 * * * *$ & $120 * *$ & $75^{*}$ \\
\hline 23 & P023 & $150 * * *$ & $130 * * * *$ & $120 * *$ & $70 *$ \\
\hline 24 & P024 & $150 * * *$ & $110 * * * *$ & $110^{*}$ & $80 * *$ \\
\hline 25 & P025 & $160 * * * *$ & $120 * * * *$ & $120 * *$ & $80 * *$ \\
\hline 26 & P026 & $145 * * *$ & $120 * * * *$ & $120 * *$ & $70 *$ \\
\hline 27 & P027 & $160 * * * *$ & $130 * * * *$ & $120 * *$ & $80 * *$ \\
\hline
\end{tabular}

\begin{tabular}{|c|c|c|c|c|c|}
\hline 28 & $\mathrm{P} 028$ & $165 * * * *$ & $120 * * * *$ & $110^{*}$ & $80 * *$ \\
\hline 29 & $\mathrm{P} 029$ & $140 * * *$ & $110 * * * *$ & $120 * *$ & $75 *$ \\
\hline 30 & $\mathrm{P} 030$ & $160 * * * *$ & $130 * * * *$ & $110^{*}$ & $70^{*}$ \\
\hline 31 & $\mathrm{P} 031$ & $150 * * *$ & $130 * * * *$ & $120 * *$ & $80 * *$ \\
\hline 32 & $\mathrm{P} 032$ & $160 * * * *$ & $100 * * * *$ & $120 * *$ & $75 *$ \\
\hline
\end{tabular}

Sumber : Data Primer, 2019

Keterangan:

* Sistolik Normal $(<120 \mathrm{mmHg})$

* Diastolik Normal (<80 mmHg)

** Sistolik Pre Hipertensi (120-139 mmHg)

**Diastolik Pre Hipertensi $(80-89 \mathrm{mmHg}$ )

*** Sistolik Stadium I Hipertensi (140-159 mmHg) dan

***Diastolik Stadium I Hipertensi (90-99 mmHg)

**** Sistolik Stadium II Hipertensi ( $\geq 160 \mathrm{mmHg}$ )

****Diastolik Stadium II Hipertensi $(\geq 100 \mathrm{mmHg})$

Hasil pengukuran tekanan darah pada tabel 4 sebelum dilakukan terapi tertawa dan dilanjutkan dengan pemeriksaan kesehatan untuk mengetahui tanda dan gejala lainnya menunjukkan bahwa semua lansia Puncak Damai Negeri Waai mengalami tekanan darah tinggi $(100 \%)$ dan bervariasi yakni pre hipertensi sebanyak 2 lansia (7\%), hipertensi Stadium I sebanyak 19 lansia (59\%), Hipertensi Stadium II sebanyak 11 lansia (34\%). Cara penanganan yang dianjurkan dokter adalah dengan terapi farmakologi dan non farmakologi. Untuk terapi nonfarmakologi lansia penderita hipertensi dapat melakukan modifikasi gaya hidup melalui pengaturan diet hipertensi yakni diet rendah garam, olahraga ringan seperti terapi tertawa atau senam hipertensi, sedangkan bagi lansia penderita hipertensi yang memiliki riwayat genetik boleh mengkonsumsi obat penurun tekanan darah sesuai anjuran dokter. Berikut ini adalah beberapa dokumentasi kegiatan.

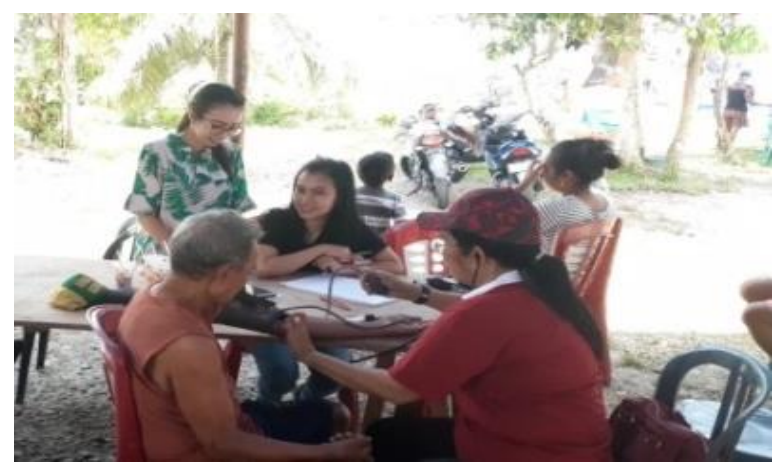

Gambar 1. Kegiatan Pemeriksaan Tekanan Darah.

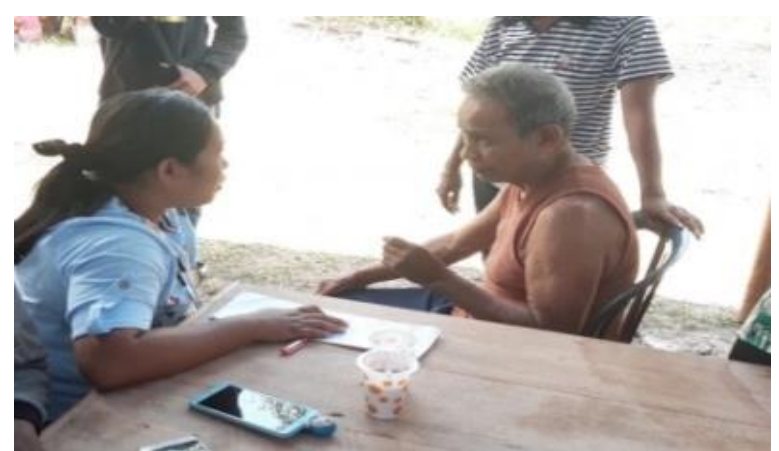

Gambar 2. Kegiatan Pemeriksaan Kesehatan Fisik. 

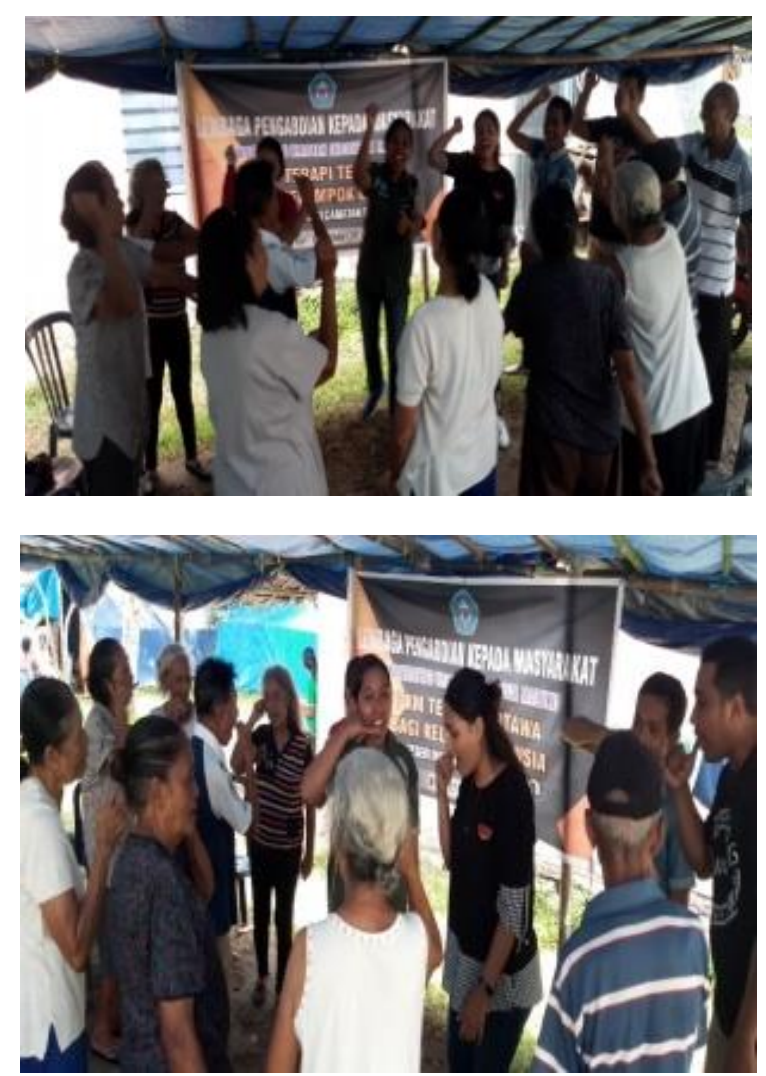

Gambar 3. Kegiatan Terapi Tertawa bagi lansia.

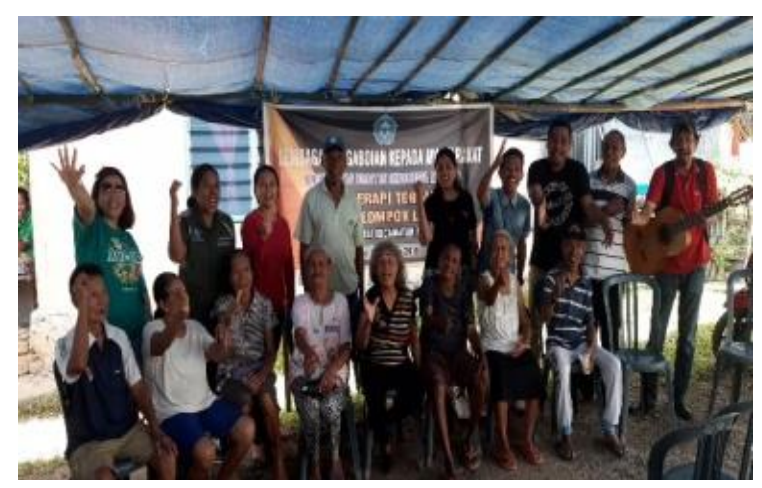

Gambar 4. Foto bersama setelah Kegiatan Terapi

Tertawa bagi lansia.

Akhir dari kegiatan Pengabdian Kemitraan Masyarakat (PkM) dilakukan penyerahan alat-alat kesehatan dasar berupa tensi meter riesester dan stetschope GEA serta buku register yang dibutuhkan oleh kelompok lansia. Sarana tersebut diserahkan kepada Raja Negeri pada tanggal 17 Oktober 2019 untuk dapat dimanfaatkan dalam memberikan pelayanan kesehatan bagi lansia.

\section{KESIMPULAN}

Kesimpulan darai Program Kemitraan Masyarakat (PkM) bagi Lansia Puncak Damai Negeri Waai Kecamatan Salahutu Kabupaten Maluku Tengah antara lain:

a. Kegiatan penyuluhan bagi lansia Puncak Damai Negeri Waai dapat meningkatkan pengetahuan lansia dengan hasil yang diperoleh rata-rata nilai pada pre-test adalah 78,278 dan sesudah mendapat penyuluhan (post-test) adalah 94,048. Hasil uji T berpasangan diperoleh nilai $p$ value yakni 0,000 menunjukkan bahwa ada perbedaan yang signifikan antara pengetahuan pre-test dan pengetahuan posttest.

b. Kegiatan training of trainer atau pelatihan bagi pengelola kelompok lansia Puncak Damai Negeri Waai telah terlaksana dengan baik dan tim PkM berharap adalah pengelola dapat mengaplikasikan terapi tertawa sebagi salah satu tindakan pencegahan yang efektif kepada lansia penderita hipertensi bahkan bagi masyarakat lainnya yang menderita hipertensi juga.

c. Kegiatan pengukuran tekanan darah sebelum dilakukan terapi tertawa dan dilanjutkan dengan pemeriksaan kesehatan untuk mengetahui tanda dan gejala lainnya menunjukkan bahwa semua lansia Puncak Damai Negeri Waai mengalami tekanan darah tinggi (100\%) dan bervariasi yakni pre hipertensi sebanyak 2 lansia (7\%), hipertensi Stadium I sebanyak 19 lansia (59\%), Hipertensi Stadium II sebanyak 11 lansia (34\%).

d. Kegiatan praktek massal yang telah dilaksanakan adalah terapi tertawa yang baik dan benar dalam pencegahan hipertensi.

\section{UCAPAN TERIMA KASIH}

Ucapan terima kasih penulis sampaikan kepada Lembaga Pengabdian Pada Masyarakat Universitas Kristen Indonesia Maluku yang telah memberikan bantuan pendanaan kepada penulis, Dekan Fakultas Kesehatan Universitas Kristen Indonesia Maluku yang telah memotivasi dalam kegiatan PkM, juga Raja Negeri Waai beserta masyarakat atas waktu dan kesempatan yang diberikan kepada Tim PkM.

\section{DAFTAR PUSTAKA}

Association, A. H. (2015). Understand Your Risk for High Blood Pressure. USA: http://www.heart.org/HEARTORG/.

Cheryl., D. (2014). Evidence-Based Guideline for the Management of High Blood Pressure in Adults . The Panel Members Appointed to the Eighth Joint National Committee (JNC 8).

Sumah, D, F. (2019). Pengaruh Terapi Tertawa Terhadap Perubahan Tekanan Darah Lansia Hipertensi di Desa Teon Nila Serua Kabupaten Maluku Tengah. Molluca Health Journal.

Flynn, J. (2016). Hypertension in the young: epidemiology, sequelae and therapy. Nephrology, Dialysis, Transplantantion Journal, 370-375.

Jerome, A . (2017). Expert Consensus Document on Hypertension in The Elderly. Journal of the American College of Cardiology.

Litbang. (2019). Data Rekam Medis. Maluku Tengah: Puskesmas Waai.

Riskesdas, T. (2018). Laporan Nasional Riset Kesehatan Dasar . Jakarta: Kementerian Kesehatan Republik Indonesia Lembaga Penerbit Badan Penelitian dan Pengembangan Kesehatan (LPB). 
Satish, D. (2012). Laughter Therapy. Journal of Pharmaceutical and Scientitic Inovation Org, 23-24.

Tage, P. K. (2014). Pengaruh Terapi Tertawa terhadap Perubahan Tekanan Darah pada Lansia dengan Hipertensi Sistolik Terisolasi di Panti Sosial Budi Agung Kupang . Indonesian Journal of Community Health Nursing.

Yogiantoro. (2016). Aging Process. Jakarta: EGC. 